“(C) 2015 IEEE. Personal use of this material is permitted. Permission from IEEE must be obtained for all other uses, in any current or future media, including reprinting/republishing this material for advertising or promotional purposes, creating new collective works, for resale or redistribution to servers or lists, or reuse of any copyrighted component of this work in other works." 


\title{
A Novel Sliding Mode Controller for DC-DC Boost Converters under Input/Load Variations
}

\author{
Jianwei Zhang, David G. Dorrell, Li Li and Ahmadreza Argha \\ Faculty of Engineering and Information Technology \\ University of Technology Sydney, Sydney, Australia \\ Jianwei.Zhang-1@student.uts.edu.au, David.Dorrell@uts.edu.au,Li.Li@uts.edu.au and Ahmadreza.Argha@uts.edu.au
}

\begin{abstract}
In this paper a simple sliding mode controller based on the averaging state space model is proposed for a DCDC boost converter. It is demonstrated to be easily implemented and has time-variant sliding coefficients. The proposed controller can effectively regulate the output voltage by controlling the switch states (through the dynamic duty cycles) even when the input voltage, load or output command varies. Furthermore the controller is independent of the inductor current and the load, although the load value is needed when designing the sliding coefficients. The constant switching frequency is maintained thus simplifying the design procedure, enhancing the regulation properties and benefiting the filter design. The controller has good dynamic response, overshoot damping and robustness. Comparative simulations are carried in MATLAB/Simulink between the proposed approach and a widely used PID controller to verify the effectiveness and feasibility of the proposed method.
\end{abstract}

Keywords-DC boost converter; sliding mode control; varying sliding coefficients; constant switching frequency; robust control

\section{INTRODUCTION}

The DC-DC converter is one of the most widely used power electronic converters; the output voltage regulation criteria are becoming increasingly stringent [1]. However, because the boost converter is a nonlinear, variable-structure and non-minimum system, designing a controller for this converter becomes complex and difficult. A suitable control technique for the boost converter should cope with its intrinsic nonlinearity and remain stable against the input and load variations while offering fast transient response [2].

The conventional regulation of a DC-DC converter output voltage is achieved by using analog control techniques but it has been stated that the interest in digital control techniques has increased dramatically [1]. Various control schemes, including linear and nonlinear control, such as current mode control [35], PID control [6-8], fuzzy control [9-12], model predictive control (MPC) [13-15], hybrid control [16-18], and sliding mode control (SMC) [2, 19-22], for DC-DC boost converters have been extensively investigated. Usually nonlinear controllers (such as MPC and fuzzy controllers) are effective although most are complex, which makes them difficult and expensive to apply in practical applications. Currently the most commonly used methods for controlling a DC-DC boost converter are linear control methods and current-mode schemes. Nevertheless the effects of the linear control are limited and designing a current mode controller is usually not an easy task. The PID controller, which is independent of the

This work is supported in part by the China Scholarship Council (File No. 201406300161). model, has a predominant role in industrial control because of its simple design and applicability to various fields, but this controller cannot meet increasing requirements for fast dynamic response and high control precision. Moreover the stability of this technique cannot be guaranteed when there exist uncertainties [22]. In contrast, as a nonlinear controller, sliding mode control is an effective means to control a DC-DC converter; this has a variable structure due to the switching characteristics [23]. SMC is independent of disturbances and constraints and it can provide advantages such as stability against large disturbances, fast dynamic response and very simple implementation. This is because this control method has the property of acting on all system state variables simultaneously [24]. SMC has proved to have improved robustness in providing consistent transient responses over a wide range of operating conditions [20]. Much work has been contributed to the SMC method in respect to power electronic converters; recent work can be found in [25-29]. However, there exist shortcomings, such as variable switching frequency and dependence on the inductor current and/or a known load [25]. The variable switching frequency always deteriorates the control performance, causes noise and makes the filter design more complex and bulky. And the dependence of the controller on the measurement of the current increases the complexity and the investment.

Motivated by the above problems, this paper aims to design a novel and simple sliding mode controller for a DC-DC boost converter based on the averaging state space model. Only continuous conduction mode is considered in this paper. The main contribution of this paper is the design of a sliding mode controller with varying sliding coefficients to regulate the output voltage via the dynamic duty ratios. In this control strategy, the sliding surface is adjusted according to different system states and variations; and since the controller is implemented using the duty cycle control, fixed constant switching frequency is maintained. This simplifies and improves the control properties. The performance of the controller under input/load/output command variations is simulated and evaluated. The proposed method is easily implemented and only requires the measurement of the actual output voltage, making the controller design less complex. In Section II the averaging state space model for continuous conduction mode of the DC-DC boost converter is addressed; in the Section III the controller is designed and the stability analysis is described and proven. Section IV puts forward simulation results followed by the conclusions in Section V. 


\section{MOdeling OF THE DC-DC Boost CONVERTER}

To implement the variable structure control, according to [24] the converter equations should be written in the form:

$$
\dot{x}=\mathbf{A} x+\mathbf{B} S+\mathbf{G}
$$

where $S$ is the switch status; $\boldsymbol{x}$ is the state vector representing the state variables; and $\mathbf{A}, \mathbf{B}$ and $\mathbf{G}$ are the state matrices. The controller scheme is based on the averaging state space model, so the model should be established first. With respect to the modeling of the DC-DC boost converter, the continuous conduction mode is considered in this paper. The basic DC-DC boost converter is shown in Fig. 1 and the equivalent circuits of the converter during $S=1$ and $S=0$ are shown in Fig. 2 . During the continuous conduction mode and when the switch is turned on $(S=1)$ the state space equations are:

$$
L \frac{d i_{L}}{d t}=u_{i} \text { and } C \frac{d u_{o}}{d t}=-\frac{u_{o}}{R}
$$

When the switch is turned off $(S=0)$ the expressions become

$$
L \frac{d i_{L}}{d t}=u_{i}-u_{o} \text { and } C \frac{d u_{o}}{d t}=i_{L}-\frac{u_{o}}{R}
$$

Combining (2) and (3) and using the state space averaging method, the overall second-order averaging model of the DC$\mathrm{DC}$ boost converter is

$$
\left[\begin{array}{c}
\frac{d i_{\mathrm{L}}}{d t} \\
\frac{d u_{\mathrm{o}}}{d t}
\end{array}\right]=\left[\begin{array}{cc}
0 & -\frac{1}{L} \\
\frac{1}{C} & -\frac{1}{R C}
\end{array}\right]\left[\begin{array}{c}
i_{\mathrm{L}} \\
u_{\mathrm{o}}
\end{array}\right]+\left[\begin{array}{c}
\frac{u_{\mathrm{o}}}{L} \\
-\frac{i_{\mathrm{L}}}{C}
\end{array}\right] S+\left[\begin{array}{c}
\frac{u_{\mathrm{i}}}{L} \\
0
\end{array}\right]
$$

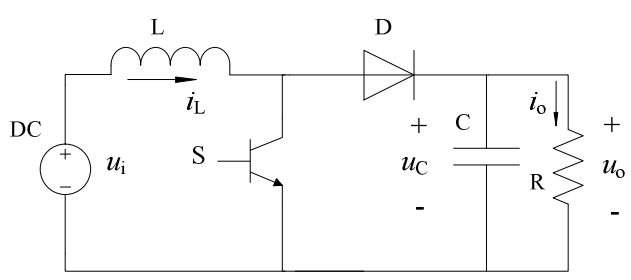

Fig. 1. General topology of DC-DC boost converter.
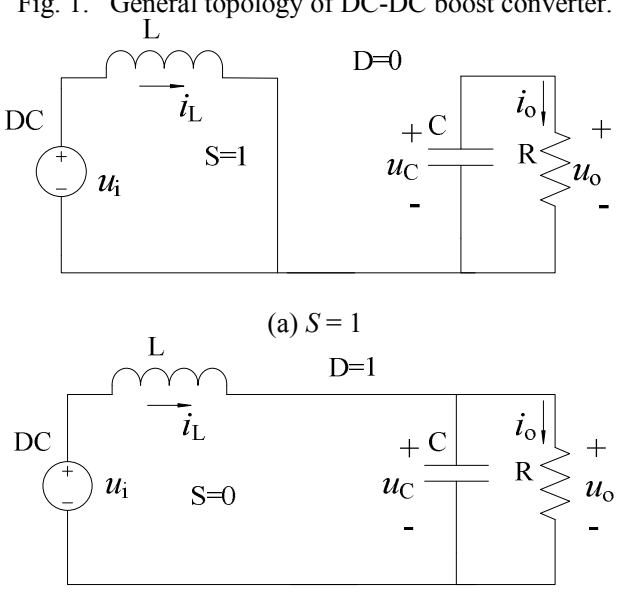

(b) $S=0$

Fig. 2. Equivalent circuits of converter during (a) $S=1$ and (b) $S=0$.

In order to guarantee that the DC-DC boost converter operates in continuous conduction mode the parameters of the elements should be selected properly. $L$ must be above the critical value of the continuous conduction mode and $C$ is chosen using the output ripple limitation. The critical values for the inductor is $L_{c}$ and capacitor is $C_{e}$; these are calculated using

$$
\begin{aligned}
L_{c} & =\frac{R}{2} d(1-d)^{2} T_{\mathrm{S}} \\
C_{e} & =\frac{u_{\mathrm{oe}} d T_{\mathrm{S}}}{R \Delta u_{\mathrm{oe}}}
\end{aligned}
$$

where $R$ is the load resistor; $d$ is the duty ratio of the PWM signal; $T_{S}=1 / f_{S}$ is the switching period; $u_{o e}$ is the desired output voltage and $\Delta u_{o e}$ is the ripple limit of the output voltage.

\section{CONTROLlER DeSIGN AND STABILITY ANALYSIS}

\section{A. Controller Design}

Generally the output voltage of the DC-DC boost converter should be regulated to keep a steady constant level even when the input voltage, output load and/or output command vary. According to the sliding mode control theory the time-variant proportional sliding function of the proposed SMC in the state space is designed as

$$
S_{S}=k_{1}(\mathrm{t}) \times\left(u_{o e}-u_{o}\right)
$$

where $k_{1}(t)>0$ is the sliding coefficient which can be designed as the constant or time-variant according to the different commands, meanwhile it should be selected properly to meet the existence condition, the reaching/hitting condition, and the stability condition. Because $k_{1}(t)$ is the constant piecewise during different steady states in this control approach, its derivative is zero during any steady states. Therefore the differential sliding function (or the first-order trending path) is expressed by (8).

$$
\dot{S}_{S}=-k_{1}(t) \dot{u}_{o}
$$

which results in the equivalent control described by below.

$$
u_{e q}=1-\frac{u_{o}}{R i_{L}}
$$

Then the corresponding trending law is defined by (10),

$$
S_{\text {law }}=-k_{2}(t)\left(u_{o e}-u_{o}\right)
$$

and the trending speed is able to be regulated via tuning the coefficient $k_{2}(t)>0$.

For the general sliding mode control of the converters, the general control law, which must be capable of controlling the output of the system to track the reference values, is defined by

$$
u=\left\{\begin{array}{l}
u^{+}, \text {if } S_{S}>0 \\
u^{-}, \text {if } S_{S}<0
\end{array}\right.
$$

Substituting the averaging state space model of the system into the rending law, the dynamic duty cycles for PWM generation can be directly obtained:

$$
0<d(t)=1-\frac{k_{1} u_{i}+\sqrt{k_{1}^{2} u_{i}^{2}+k \cdot u_{o} \cdot\left(u_{o e}-u_{o}\right)}}{2 k_{1} u_{o}}<1
$$

where

$$
k=\frac{4 L}{R}\left(C R k_{2}^{2}-k_{1} k_{2}\right)
$$

Obviously when the error between the reference output and the actual output voltage is $0,(12)$ becomes:

$$
d(t)=1-u_{i} / u_{o e}
$$


which is the inherently general steady-state relationship (independent of the control schemes) between the input and output voltage for the DC-DC boost converters. It can be seen that the controller is independent of the inductor current, and load knowledge is only needed when designing the sliding coefficients.

\section{B. Stability Analysis}

1) The reaching condition description: With the designed control laws in (10), (11) and (12), and the initial starting points in the state space, arbitrary external points (either in negative or positive area), or on the sliding surface $S_{S}$, will reach the sliding surface $S_{S}$ in a finite time $t$. This means that the designed control law meets the reaching condition.

Proof: If $S_{S}>0$ the actual output voltage is below the reference voltage. Under the designed control law the dynamic duty cycles are controlled to be greater than the theoretically critical value $\left(1-u_{i} / u_{o e}\right)$, and as a consequence, the output voltage will increase to the reference value. If $S_{S}<0$, the actual output voltage is above the desired voltage, and according to the proposed control law, the duty cycles are regulated to be lower than the critical value. As a result the actual output voltage will decrease and reach the sliding surface sooner or later. If $S_{S}=0$, the actual output voltage is as expected and the duty cycle will be kept at the critical value and the output remains as the reference value. Hence the designed control law is effective and complies with the reaching condition.

2) The existence condition description: When the representing points of the system are in the vicinity of the sliding surface, under the specific system parameters, if the sliding coefficients $k_{1}(t)$ and $k_{2}(t)$ are within the set $\Theta$ :

$$
\Theta=\left\{k_{1}(t), k_{2}(t) \mid-a<\frac{L}{R C}\left(R C k_{2}^{2}-k_{1} k_{2}\right)<a\right\}
$$

where $a=\left(u_{\mathrm{o}}-u_{\mathrm{i}}\right) /\left|u_{\mathrm{oe}}-u_{\mathrm{o}}\right|>0$, then the sliding mode exists and any system trajectories in the state space will be directed to and then slide across the sliding surface $S_{S}=0$, that is, the following existence condition is satisfied:

$$
\lim _{S_{S} \rightarrow 0} S_{S} \dot{S}_{S} \leq 0
$$

Proof: For the proof of the existence condition the following cases are considered:

- CASE 1: The representing points are in the positive vicinity of the sliding surface, i.e., $S_{S} \rightarrow 0^{+}$, which leads to $S_{S}>0$, higher duty cycles and increasing output voltage $\left(\begin{array}{ll}u & >\end{array}\right)$. Under this situation:

$$
\lim _{S_{S} \rightarrow 0^{+}} \dot{S}_{S}=\lim _{S_{S} \rightarrow 0^{+}}-\dot{u}_{o}<0
$$

- CASE 2: The representing points are in the negative vicinity, i.e., $S_{S} \rightarrow 0^{-}$, which leads to $S_{S}<0$, lower duty cycles and decreasing output voltage $\left(\begin{array}{ll}u_{\mathrm{o}}<0\end{array}\right)$ thus:

$$
\lim _{S_{S} \rightarrow 0^{+}} \dot{S}_{S}=\lim _{S_{S} \rightarrow 0^{+}}-\dot{u}_{o}>0
$$

- CASE 3: When the output voltage reaches the desired reference voltage, obviously $S_{\mathrm{s}}=0$.

Based on the above three cases, overall we have:

$$
\lim _{S_{S} \rightarrow 0} S_{S} \dot{S}_{S} \leq 0 .
$$

In summary, if $k_{1}$ and $k_{2}$ are selected to be within the real number set $\Theta$, the sliding surface satisfies the existence condition (16), and the system representing points can slide across or on the designed sliding surface. It is worth noting that, at the beginning of the control, the actual output voltage $u_{o}$ can be very small (starting from 0 ); but when the system is stabilized around the reference value, the difference between the reference and actual output is not significant. Therefore according to the difference system states, the coefficients of the sliding surface can be adjusted accordingly to improve the system performance. This is the time-variant sliding coefficients concept presented here.

Remark 1: Observe the divergence function or divergence of the system (4), the following result is obtained:

$$
\Delta f=\frac{\partial\left(d i_{L} / d t\right)}{\partial i_{L}}+\frac{\partial\left(d u_{o} / d t\right)}{\partial u_{o}}=-\frac{1}{R C}<0
$$

This illustrates that the nonlinear system has a dissipative structure and all the state trajectories will finally be limited to an infinitely small subset. This confirms that original circuit is passive and benefits the design of control laws for nonlinear and linear systems.

In addition to meeting the existence and reaching conditions, the designed sliding surface should also abide by the stability condition. It can be demonstrated that the stability condition is inherently met through the design of the sliding coefficients to meet the expected dynamic characteristics [5]. By meeting the stability condition, the designed sliding surface will always direct all the state trajectories toward a stabilized point where equilibrium points exist.

3) The system stability description: When (15) is true and the equilibrium points for the system are $x_{\mathrm{e}}$ as by (18)

$$
x_{e}=\left[i_{e}, u_{e}\right]^{T}=\left[\frac{u_{e}{ }^{2}}{R u_{i}}, u_{e}\right]^{T}
$$

then the system is asymptotically stable on the equilibrium points.

Proof: The purpose of the controller is to keep the system variables move along the sliding surface, therefore, ideally, the error between the reference voltage and the actual output voltage is zero. This leads to:

and

$$
\begin{gathered}
S_{S}=k_{1}\left(u_{o e}-u_{o}\right)=0 \\
d(t)=1-\frac{u_{i}}{u_{o e}}
\end{gathered}
$$

According to Lyapunov's stability theory, the candidate Lyapunov function (scalar quadratic function) is:

$$
V(x)=\frac{1}{2} e^{T} Q e=\frac{1}{2}\left(x-x_{e}\right)^{T} Q\left(x-x_{e}\right)
$$

where $x=\left[i_{\mathrm{L}} u_{\mathrm{o}}\right]^{T}$ are the state variables, $Q$ is a diagonal matrix $=\left[a_{1} 0 ; 0 a_{2}\right]\left(a_{1}, a_{2}>0\right)$ and markedly $V\left(i_{e}, u_{e}\right)=0$.

According to (21), further on (22) is obtained:

$$
V\left(i_{L}, u_{o}\right)=\frac{1}{2}\left[a_{1}\left(i_{L}-i_{e}\right)^{2}+a_{2}\left(u_{o}-u_{e}\right)^{2}\right]
$$

Therefore, for any $x \neq x_{e}, V>0$, and when $x=x_{e}, V=0$. Hence the constructed function $V$ is positive definite. Then the derivative of (21) is considered: 


$$
\begin{aligned}
& \dot{V}=\frac{1}{2} \dot{e}^{T} Q e+\frac{1}{2} e^{T} Q \dot{e} \\
& =-a_{2} \frac{k_{2}}{k_{1}}\left(u_{\mathrm{o}}-u_{\mathrm{e}}\right)^{2}+\frac{a_{2}}{L}\left[u_{\mathrm{i}}-(1-S) u_{\mathrm{o}}\right]\left[i_{\mathrm{L}}-\frac{u_{\mathrm{e}}{ }^{2}}{R u_{\mathrm{i}}}\right]
\end{aligned}
$$

From the energy conservation law (ignoring the losses) when $u_{o}>u_{e}$, then $\left[u_{i}-(1-S) u_{o}\right]<0$. This leads to $i_{L}>i_{e}$, resulting in $\left[i_{L}-u_{e}^{2} / R u_{i}\right]>0$. Else when $u_{o}<u_{e}$, then $\left[u_{i}-(1-\right.$ $\left.S) u_{o}\right]>0$, giving $i_{L}<i_{e}$, which results in $\left[i_{L}-u_{e}^{2} / R u_{i}\right]<0$. In summary, for any $x \neq x_{e}(23)$ is negative and when $x=x_{e}(23)$ is zero. Therefore (23) is negative definite. In conclusion, the candidate function is a Lyapunov function and the system abides by the Lyapunov stability requirements. Therefore the system is asymptotically stable on the equilibrium points.

Remark 2: When the system is stabilized on the equilibrium points, by inspection of the energy conservation law and neglecting the lost energy, the output and input powers equate:

$$
P_{\text {in }}=u_{i} i_{e}=P_{\text {out }}=\frac{u_{e}^{2}}{R}
$$

Consequently the same equilibrium points as (18) are obtained.

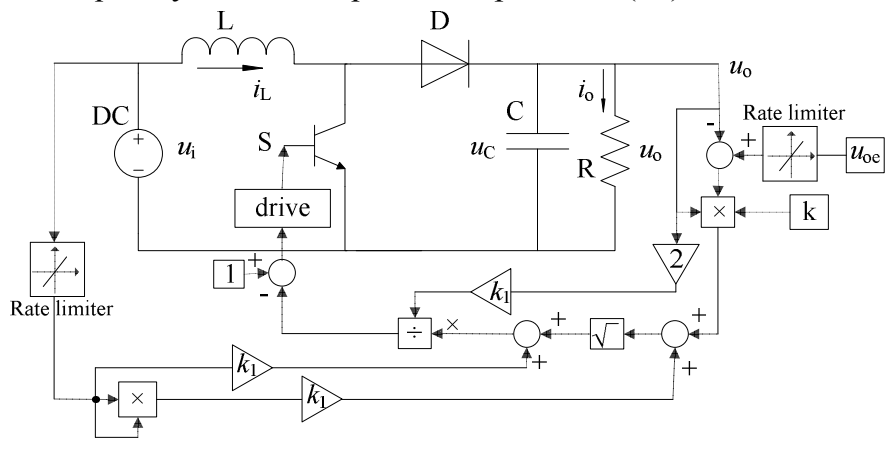

Fig. 3. Proposed SMC controller for the converter ( $k$ is shown in (13)).

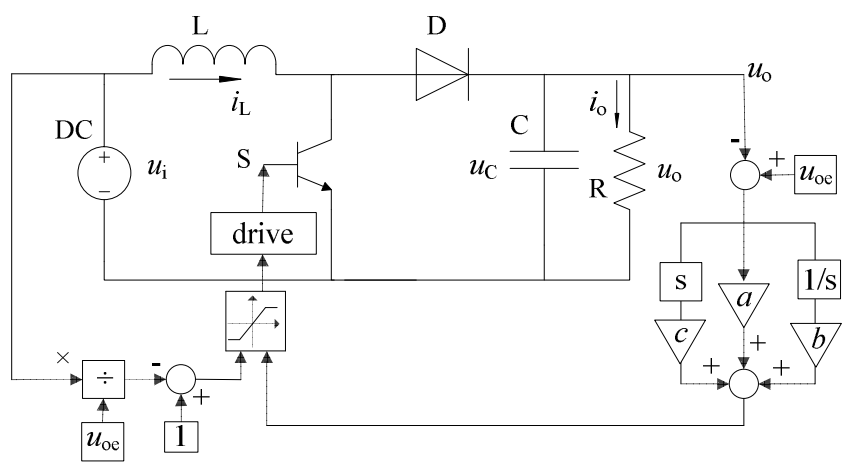

Fig. 4. Dynamic-duty-cycle PID controller for the converter.

Based on the above discussion, the proposed SMC controller is designed and illustrated in Fig. 3.

In order to investigate the comparative study, a dynamicduty-cycle PID controller scheme was designed; this is outlined in Fig. 4. In this scheme the duty cycle of the PWM generator is related to the input voltage. That is, if the input voltage changes the duty cycle changes accordingly.

Compared to the PID controller it can be seen that the proposed method is also easily implemented. In next section the simulation is implemented and the results are analyzed.

\section{Simulation AND RESUlts}

Using MATLAB/Simulink, the general PWM modulation (gPWM), dynamic-duty-cycle PID controller (dPID) and the proposed SMC controller are simulated and compared in this section. The parameters of the elements in simulated DC-DC boost converter are shown in Table I.

In the first scenario, without any variations, gPWM, dPID and designed SMC are used to control the converter; the results are shown in Fig. 5. The desired output voltage was set to a constant $100 \mathrm{~V}$ and the constant sliding coefficients $k_{1}, k_{2}$ for the SMC are 1 and 3000. For SMC, both the constant and varying sliding coefficients (CSC and VSC) are simulated and their results are shown in Fig. 5 (c1) and (c2) separately.

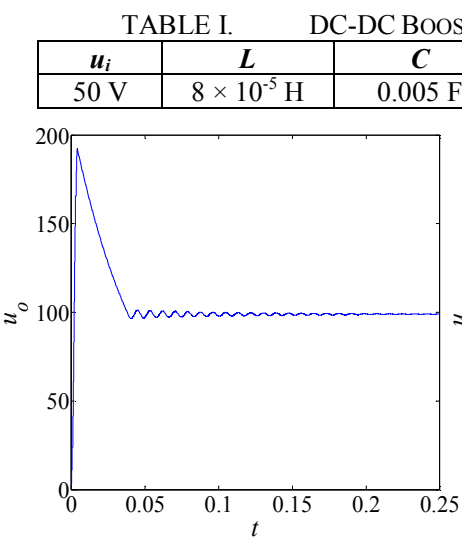

(a)gPWM controller

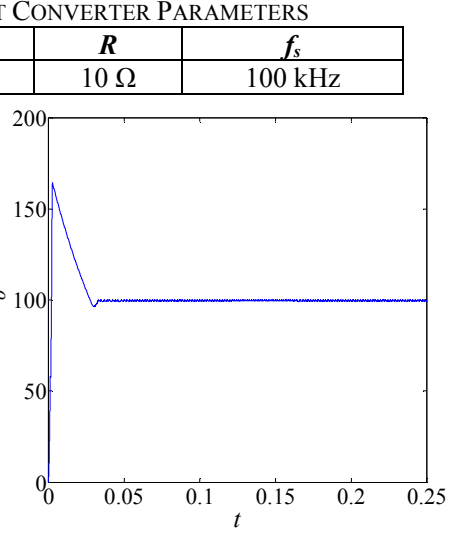

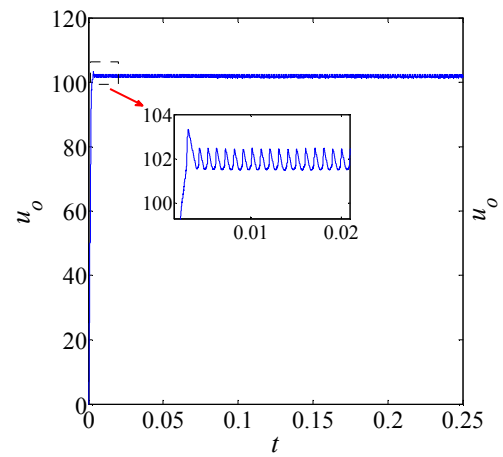

(c1)SMC with CSC

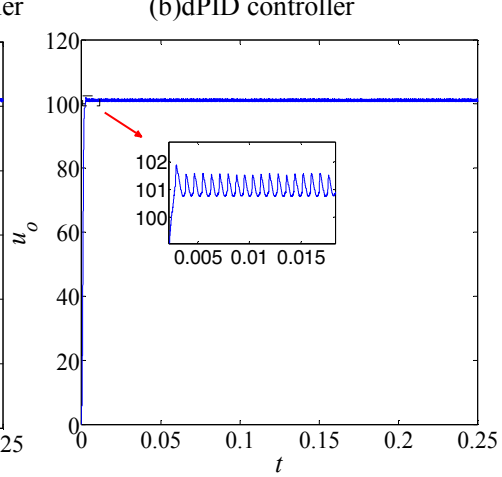

(c2) SMC with VSC
Fig. 5. Results of the converter controlled by (a) gPWM (b) dPID (c) SMC.

From the results it is clear that both dynamic-duty-cycle PID control and SMC have better performance than general PWM modulation in terms of overshooting. With Regards to the dPID controller, the actual output voltage is slightly lower than expected. However, it can be noted that the dynamic response of the proposed SMC is very fast and the performance is effective and better, although the actual output is a little higher (approximately $2 \%$ for CSC and $1 \%$ for VSC) than the desired output voltage. The performance of the SMC with VSC is better than that with CSC. Because of the poor performance with general PWM modulation, it was not evaluated while all SMCs are with varying sliding coefficients. In the next case, load variation is considered. The dynamic dPID controller simulation and designed SMC are implemented. The load doubles at time $\mathrm{t}=0.1 \mathrm{~s}$. The results are given in Fig. 6 . 


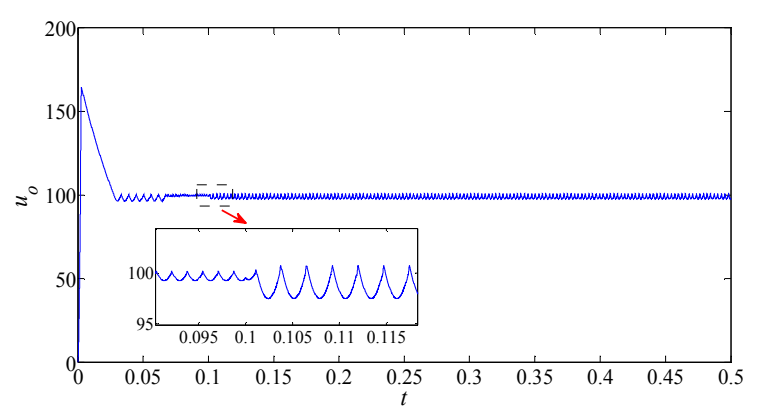

(a) Result of dPID controller

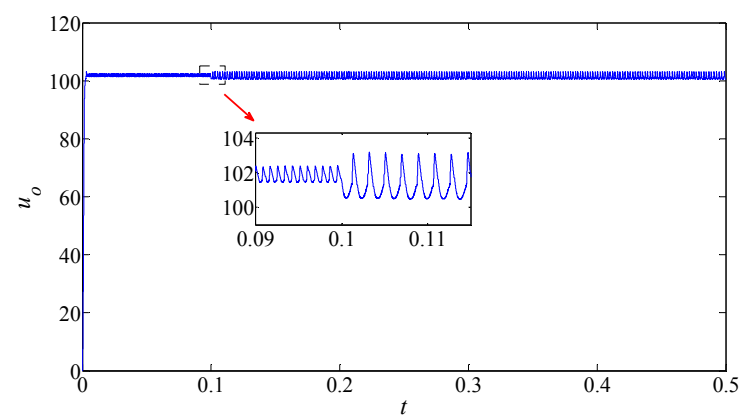

(b) Result of SMC controller with VSC.

Fig. 6. Converter (a) dPID (b) SMC response to the load variation.

As can be seen there are oscillations when the load varies at $t=0.1 \mathrm{~s}$ for both dPID and SMC. However, clearly, the SMC is advantageous with regards to the dynamic response and overshooting. In the next scenario, the input is varied in the simulation for the dPID and SMC controllers; the outputs are given in Fig. 7. The input voltage decreases from $50 \mathrm{~V}$ to $40 \mathrm{~V}$ at the time $t=0.2 \mathrm{~s}$.

In the last simulation, the controller responses to the both increasing and decreasing voltage demands at $t=0.3 \mathrm{~s}$ are

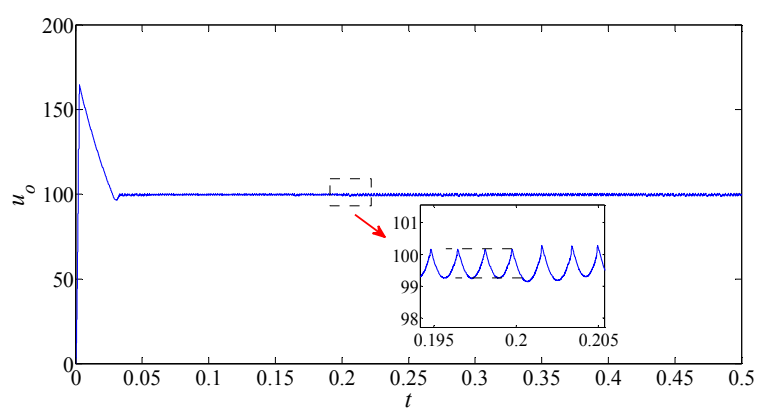

(a) Result of dPID controller.

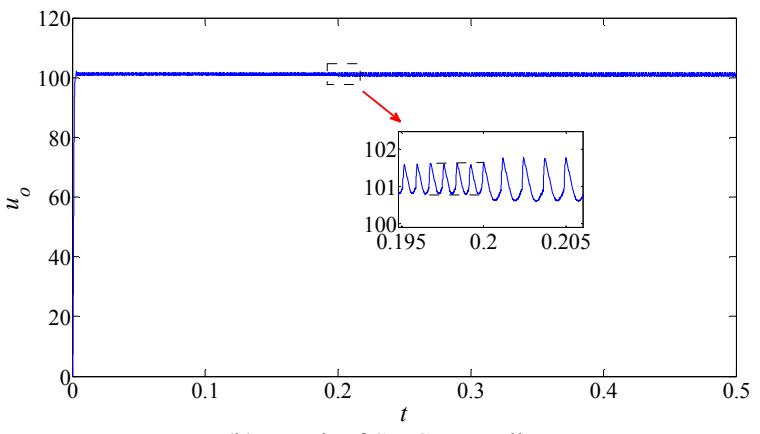

(b) Result of SMC controller.

Fig. 7. Controller (a) dPID (b) SMC response to the input variation. simulated and their results are given in Fig. 8. In the first situation the output command increases from $100 \mathrm{~V}$ to $110 \mathrm{~V}$ at $t=0.3 \mathrm{~s}$, while in the second simulation the output command decreases from $100 \mathrm{~V}$ to $90 \mathrm{~V}$ at $t=0.3 \mathrm{~s}$. Due to the limitation of the existence condition, the rate of change of the output command voltage is limited to $[-1000,1000]$ for the SMC controller.

It is demonstrated that the proposed SMC with varying sliding coefficients is effective in regulating the output voltage under input variation, changing loads, and varying output command. The controller has small overshoot and its dynamic response is very fast which are superior to the PID controller. However, the actual output voltage of the designed SMC is slightly higher than the reference value.

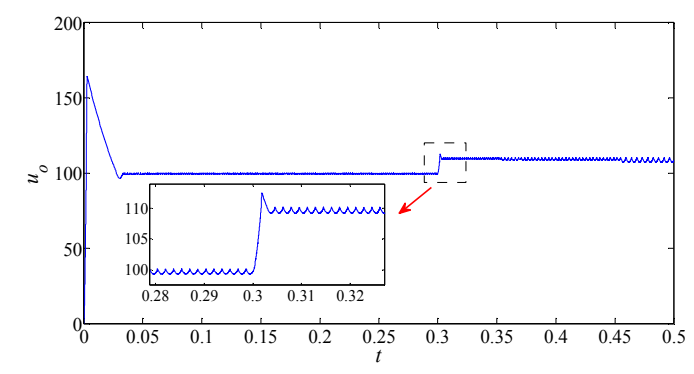

(a1) Result of dPID controller when output command increases.

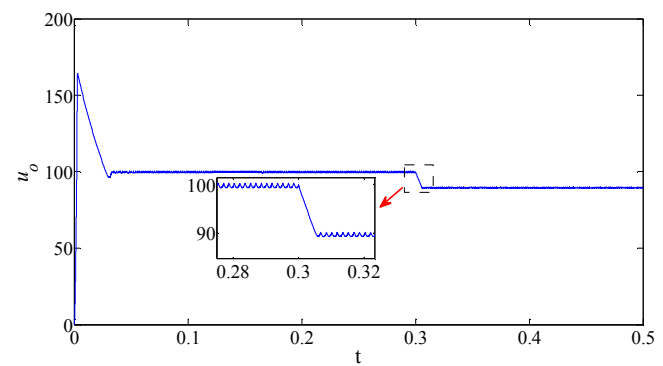

(a2) Result of dPID controller when the output command decreases.

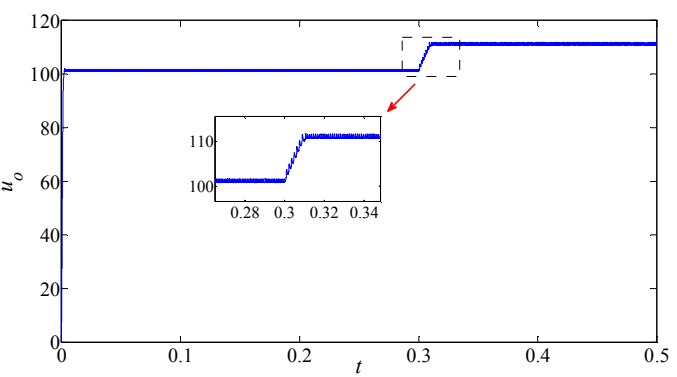

(b1) Result of SMC controller when the output command increases.

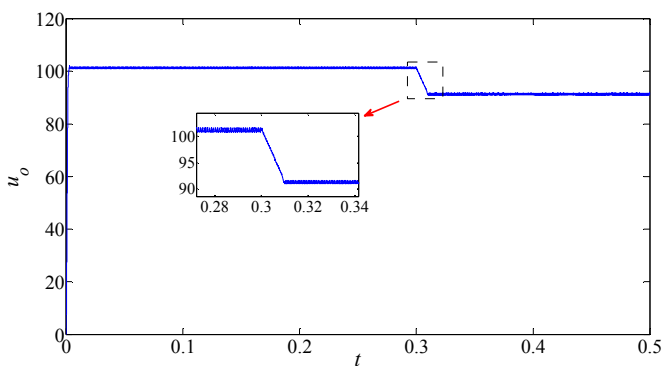

(b2) Result of SMC controller when the output command decreases.

Fig. 8. Converter (a) dPID (b) SMC response to varying output command. 


\section{CONCLUSIONS}

Because of the inherent operating characteristics of the semiconductor switch, the DC-DC converter is nonlinear. The sliding mode controller is a variable-structure nonlinear controlling strategy and is known for good robustness, fast dynamic response (under input/load varying conditions) and simple design. Therefore in order to achieve large signal stability and fast dynamic response, the sliding mode control method was proposed in this paper in order to improve the performance of the converter. The effect of the parasitic elements and the losses are not analyzed in this work. Models are developed for a DC-DC boost converter operating in the continuous conduction mode and these employ a time-variantcoefficient sliding mode control to regulate the output voltage by controlling the duty cycle with fixed constant switching frequency. In the proposed approach the sliding coefficients are adjusted according to the changing of the system parameters. The reaching condition and the existence condition are described and proven; also, a Lyapunov function is constructed to address the stability of the system on the equilibrium point. The dynamic-duty-cycle PID controller is applied in order to carry out a comparative analysis. From the stability analysis and the simulated results, it can be concluded that the proposed controller can be easily implemented and it has fast dynamic response, small overshoot and good robustness. Simulation results verify the effectiveness and feasibility of the system. Experimental work will be conducted to test the feasibility of the proposed controller.

\section{REFERENCES}

[1] G. Feng, E. Meyer, and YF. Liu, "A new digital control algorithm to achieve optimal dynamic performance in DC-to-DC converters," IEEE Trans. Power Electron., vol 22, no. 4, pp. 1489-1498, 2007.

[2] H. Guldemir, "Sliding mode control of DC-DC boost converter," $J$. Appl. Sci., vol. 5, no. 3, pp. 588-592, 2005.

[3] S. Chattopadhyay and S. Das, "A digital current-mode control technique for DC-DC converters," IEEE Trans. Power Electron., vol. 21, no. 6, pp. 1718-1726, 2006.

[4] B. Bryant and M. K. Kazimierczuk, "Voltage loop of boost PWM DCDC converters with peak current-mode control," IEEE Trans. Circuits Syst. I, Reg. Papers, vol. 53, no. 1, pp. 99-105, 2006.

[5] P. Cooke, "Modeling average current mode control," IEEE Applied Power Electronics Conf. and Expo. (APEC), 2000, pp. 256-262.

[6] L. Guo, J. Y. Hung and R. M. Nelms, "PID controller modifications to improve steady-state performance of digital controllers for buck and boost converters," IEEE Applied Power Electronics Conf. and Expo. (APEC), 2002, pp. 381-388.

[7] Y.I. Son and I.H. Kim, "Complementary PID controller to passivitybased nonlinear control of boost converters with inductor resistance," IEEE Trans. Control Syst. Technol., vol. 20, no. 3, pp.826-834, 2012.

[8] S. Arulselvi, S., G. Uma, and M. Chidambaram, "Design of PID controller for boost converter with RHS zero," 4th Int. IEEE Power Electronics and Motion Control Conf. (IPEMC), 2004, pp. 532-537.

[9] L Guo, J. Y. Hung, and R. M. Nelms, "Comparative evaluation of sliding mode fuzzy controller and PID controller for a boost converter," Elect. Power Syst. Research, vol. 81, no. 1, pp. 99-106, 2011.
[10] K. Viswanathan, D. Srinivasan, and R. Oruganti, "A universal fuzzy controller for a non-linear power electronic converter," IEEE Int. Conf. Fuzzy Systems, 2002, pp. 46-51.

[11] S. El Beid and S. Doubabi, "DSP-based implementation of fuzzy output tracking control for a boost converter," IEEE Trans. Ind. Electron., vol. 61, no. 1, pp. 196-209, 2014.

[12] C. Elmas, O. Deperlioglu and H. H. Sayan, "Adaptive fuzzy logic controller for DC-DC converters," Expert Syst. with Applicat., vol. 36, no. 2, pp. 1540-1548, 2009.

[13] M. Lazar and R. De Keyser. "Non-linear predictive control of a DC-toDC converter," Symp. Power Electronics, Electrical Drives, Automation \& Motion (SPEEDAM), Capri, Italy, 2004.

[14] A. G. Beccuti, S. Mariethoz, S. Cliquennois, S. Wang and M. Morari, "Explicit model predictive control of DC-DC switched-mode power supplies with extended Kalman filtering," IEEE Trans. Ind. Electron., vol. 56, no. 6, pp. 1864-1874, 2009.

[15] P. Karamanakos, T. Geyer and S. Manias, "Direct voltage control of dc$\mathrm{dc}$ boost converters using enumeration-based model predictive control," IEEE Trans. Power Electron., vol. 29, no. 2, pp. 968-978, 2014.

[16] C. Sreekumar and V. Agarwal, "A hybrid control algorithm for voltage regulation in DC-DC boost converter," IEEE Trans. Power Electron., vol. 55 , no. 6 , pp. 2530-2538, 2008.

[17] S. Mariéthoz, S. Almér, M. Bâja and A. G. Beccuti, et al., "Comparison of hybrid control techniques for buck and boost DC-DC converters," IEEE Trans. Control Syst. Technol., vol. 18, no. 5, pp. 1126-1145, 2010.

[18] P. Gupta and P. Amit, "Hybrid mode-switched control of DC-DC boost converter circuits." IEEE Trans. Circuits and Syst. II: Exp. Briefs, vol. 52, no. 11, pp. 734-738, 2005.

[19] S.-C. Tan, Y.-M. Lai and C. K. Tse, "A unified approach to the design of PWM-based sliding-mode voltage controllers for basic DC-DC converters in continuous conduction mode," IEEE Trans. Circuits and Syst. I: Reg. Papers, vol. 53, no. 8, pp. 1816-1827, 2006.

[20] S.-C. Tan, Y.-M. Lai and C. K. Tse, "General design issues of slidingmode controllers in DC-DC converters," IEEE Trans. Ind. Electron., vol. 55 , no. 3, pp. 1160-1174, 2008,

[21] D. Cortés, J. Alvarez and J. Alvarez, "Robust control of the boost converter," IEEE Int. Conf. on Industrial Electronics and Control Applications (ICIECA), 2005, pp. 1-5.

[22] R.-J. Wai and L.-C. Shih, "Design of voltage tracking control for DCDC boost converter via total sliding-mode technique," IEEE Trans. Ind. Electron., vol. 58, no. 6, pp. 2502-2511, 2011.

[23] Y. He and F. L. Luo, "Sliding-mode control for dc-dc converters with constant switching frequency," Proc. IEE Control Theory and Applicat. vol. 153, no. 1, pp. 37-45, 2006.

[24] P. Mattavelli, L. Rossetto, G. Spiazzi and P. Tenti, "General-purpose sliding-mode controller for DC/DC converter applications," IEEE 24th Annu. Power Electronics Specialists Conf., 1993, pp. 609-615.

[25] S. Oucheriah and L. Guo, "PWM-based adaptive sliding-mode control for boost DC-DC converters," IEEE Trans. Ind. Electron., vol. 60, no. 8, pp. 3291-3294, 2013.

[26] Y. Zhao, W Qiao and D. Ha, "A sliding-mode duty-ratio controller for DC/DC buck converters with constant power loads," IEEE Trans. Ind. Appl., vol. 50, no. 2, pp. 1448-1458, 2014.

[27] Z. Chen, "PI and sliding mode control of a Cuk converter," IEEE Trans. Power Electron., vol. 27, no. 8, pp. 3695-3703, 2012.

[28] J. Monteiro, J. Fernando Silva, S. F. Pinto and J. Palma. "Linear and sliding-mode control design for matrix converter-based unified power flow controllers," IEEE Trans. Power Electron., vol. 29, no. 7, pp. 33573367, 2014.

[29] Y. B. Shtessel, A. S. I. Zinober and I. A. Shkolnikov. "Sliding mode control of boost and buck-boost power converters using method of stable system centre," Automat., vol. 39, no. 6, pp. 1061-1067, 2003. 